\title{
Overcoming HSP27-mediated resistance by altered dimerization of HSP27 using small molecules
}

\author{
Jee Hye Kim ${ }^{1, *}$, Ye Jin Jung, ${ }^{1,}$, Byeol Choi ${ }^{1}$, Na Lim Lee ${ }^{1}$, Hae Jun Lee ${ }^{2}$, Soo Yeon \\ Kwak $^{3}$, Youngjoo Kwon ${ }^{1}$, Younghwa $\mathrm{Na}^{3}$, Yun-Sil Lee ${ }^{1}$ \\ ${ }^{1}$ Graduate School of Pharmaceutical Sciences, Ewha Womans University, Seoul, 120-720, Korea \\ ${ }^{2}$ Division of Radiation Effects, Korea Institute of Radiological and Medical Sciences, Seoul, 139-706, Korea \\ ${ }^{3}$ College of Pharmacy, CHA University, Pocheon, 487-010, Korea \\ ${ }^{*}$ These authors contributed equally to this work
}

Correspondence to: Yun-Sil Lee, email: yslee0425@ewha.ac.kr Younghwa $\mathrm{Na}$, email: yna7315@cha.ac.kr

Keywords: HSP27 inhibition, altered dimerization, overcoming resistance, combination therapy

Received: January 04, 2016

Accepted: July 06, 2016

Published: July 16, 2016

\section{ABSTRACT}

Heat shock protein 27 (HSP27, HSPB1) is an anti-apoptotic protein characterized for its tumorigenic and metastatic properties, and now referenced as a major therapeutic target in many types of cancer. The biochemical properties of HSP27 rely on a structural oligomeric and dynamic organization that is important for its chaperone activity. Down-regulation by small interfering RNA or inhibition with a dominant-negative mutant efficiently counteracts the anti-apoptotic and protective properties of HSP27. However, unlike other HSPs such as HSP90 and HSP70, small molecule approaches for neutralization of HSP27 are not well established because of the absence of an ATP binding domain. Previously, we found that a small molecule, zerumbone (ZER), induced altered dimerization of HSP 27 by cross linking the cysteine residues required to build a large oligomer, led to sensitization in combination with radiation. In this study, we identified another small molecule, a xanthone compound, more capable of altering dimeric HSP27 than ZER and yielding sensitization in human lung cancer cells when combined with HSP90 inhibitors or standard anticancer modalities such as irradiation and cytotoxic anticancer drugs. Therefore, altered dimerization of HSP27 represents a good strategy for anticancer therapy in HSP27overexpressing cancer cells.

\section{INTRODUCTION}

Molecular chaperones, including heat shock proteins (HSPs), help tumor cells cope with stressinduced misfolded proteins and play prominent roles in cellular signaling and transcriptional regulatory networks. HSP27 (HSP27 [human form] and HSP25 [murine form]) has been identified as a critical mediator in cancer progression, preventing apoptosis in transformed cells [1-4]. In a wide range of human cancers, increased levels of HSP27 are closely associated with tumorigenesis, metastasis, resistance to anticancer therapeutics, and, accordingly, poor prognosis $[4,5]$. Therefore, HSP27 inhibition as an adjuvant of radio- and chemo-therapy has clinical implications. HSP27 gene silencing by OGX-427, a second-generation antisense oligonucleotide, induces sensitization in radio- and chemo-resistant cancer cells [6]. Moreover, OGX-427 overcomes treatment resistance by HSP90 inhibitors, including natural compounds such as geldanamycin and its analog 17-allylamino17-demethoxy-geldanamycin (17-AAG), or synthetic compounds including PF-04928473, due to compensatory mechanisms involving activation of HSP27 [7, 8]. Accordingly, HSP27 inhibition is an attractive therapeutic target.

Although an appealing cancer target, HSP27 acts through an ATP-independent mechanism and is therefore not susceptible to inhibition by $17-\mathrm{AAG}_{-}$ derived small molecules. Recently, a small molecule triazole ribonucleoside was reported to induce apoptosis in pancreatic cancer cells by decreasing HSP27 levels; however the exact mechanism and the specificity of the 
drug against HSP27 knockdown remain unclear [4, 9-11]. Aside from this compound, no small molecules have been developed as HSP27 inhibitors for cancer therapy, although functional HSP27 inhibition may be a good strategy for combination therapy with HSP90 inhibitors, chemotherapeutic agents, or radiation. Strategies to inhibit HSP27 at the mRNA level offer an alternative approach to inhibiting targets, including short interfering RNA (siRNA) $[12,13]$ or antisense oligonucleotides such as OGX-427 to suppress target levels [14]. While siRNA can potently and specifically inhibit target genes in vitro, cellular uptake and activity in vivo require drug delivery systems that have proven challenging and rate-limiting.

Another interesting approach to targeted inhibition of HSP27 involves the use of HSP27 peptides that interact with HSP27 and promote apoptosis induced by chemotherapeutics, similar to HSP27 silencing [15-19]. However, to make these peptides stable for in vivo and therapeutic use, further processing is needed, such as conjugation with PEG to increase molecular mass and extend the half-life of peptides by slowing renal filtration [20].

We previously demonstrated that zerumbone (ZER), a cytotoxic component isolated from a natural product, Zingiber zerumbet Smith, induced cross-linking of the HSP27 protein by insertion between the disulfide bonds of HSP27. ZER-mediated altered cross-linking of HSP27 modified normal HSP27 dimerization, which resulted in a sensitizing effect to tumors after treatment with radiation (IR). Therefore, altered cross-linking by ZER was suggested as a novel strategy for inhibition of HSP27mediated resistance [21]. In this study, we identified a more potent HSP27 cross linker, SW15, a synthetic xanthone compound which yielded stronger sensitization, when it was combined with HSP90 inhibitors. Moreover, SW15 also showed potent synergism with conventional anticancer modalities.

\section{RESULTS}

\section{The same xanthone moiety with different side chains caused different cross linking activity of HSP27}

ZER promotes cross-linking of HSP27 to form altered dimers, inhibiting oligomerization of HSP27. Because ZER is a naturally occurring compound, largescale production has limitations. Moreover, chemical characteristics of ZER are not druggable, because of low solubility and limitation of mass production. During large scale screening of HSP27 cross-linking activity using synthetic compounds (Supplementary Figure S1A), we found that xanthone moiety compounds yielded different HSP27 cross-linking activity, with variation in potency according to side chain structures (Supplementary Figure S1B). Next, we selected 3 xanthone compounds with differing side chain structures, SW13, SW15, and YK594, because they promoted different amounts of cross-linking of HSP27. SW15 displayed the strongest cross-linking activity, SW13 had less effect than SW15, and YK594 showed no cross linking activity (Figure 1A, $1 \mathrm{~B}$ and $1 \mathrm{C})$. The cytotoxic activitiy of SW13. SW15 or YK594 was weak, with IC50 values in NCI-H460 cells of $>80,23.87 \pm 1.83$ and $>80 \mathrm{uM}$, respectively, compared to taxol (Supplementary Figure S2). Moreover, HSP27 cross-linking activity disappeared when shRNA of HSP27 was stably transfected (Figure 1D), suggesting that altered cross- linking of HSP27 was HSP27-dependent. The next experiments were performed using SW15, which yielded the highest cross-linking of HSP27. To elucidate whether cross-linking of HSP27 by SW15 was specific to the HSP27 protein, we evaluated cross-linking activity of other proteins with cysteine residues that form disulfide bonds. Proteins of HSP90, HSP70, NFkB, JNK2, Akt1 and $\beta$-Actin did not form cross-linked dimer forms after treatment of SW15 (Supplementary Figure S3A). The analysis of mass spectrophotometry for the dimerized form of HSP25 (HSBP1, murine form) at approximately $50 \mathrm{kDa}$ revealed that this protein was the cross-linking form of HSP25 (Supplementary Figure S3B).

\section{The HSP27 cysteine residue is important for altered cross linking of HSP27 through the xanthone compound}

ZER-mediated altered cross linking occurs in a specific cysteine residue (position 141 in mice and 137 in humans), and so we examined whether SW15 also directly affected cross-linking of HSP27 at the same cysteine residue. The mutant form of HSP25 (we transfected the murine form of HSP25 to differentiate the expression of endogenous human HSP27), which replaces cysteine at position 141 with alanine (HSP25-C141A) and does not induce cross-linking of HSP25, was transfected. SW15 induced cross-linking of HSP25-WT, but not HSP25C141A (Figure 2A). Moreover, pretreatment with $\mathrm{N}$-acetyl cystein (NAC), a thiol reducing agent caused SW15mediated altered cross linking of HSP27 to disappear, suggesting that the cysteine residue of HSP27 is important for SW15-mediated altered cross linking of HSP27 (Figure 2B). Normal dimerization of HSP27 induced large oligomerization of HSP27 when it was detected in nonreducing gels, and not in reducing gels. However, SW15 induced cross-linking of HSP27 that was different from the common disulfide bond and inhibited the formation of normal large-size oligomers of HSP27 (Figure 2C) [21]. To determine whether altered cross-linking of HSP27 could affect binding activity with apoptotic molecules such as cytochrom c [24] or PKCdelta [17, 18], we pretreated samples with SW15 before IR and binding activity between HSP27 and cytochrome c or PKCdelta was examined at $12 \mathrm{hr}$ after IR. Increased binding activity 
between HSP27 and cytochrome c or PKCdelta after IR was inhibited by SW15 (Figure 2D). From the data, we conclude that SW15-mediated cross-linking of HSP27 was different than normal HSP27 dimerization and might prevent chaperone activity.

\section{The combination of the HSP90 inhibitors and the xanthone compound sensitized cancer cells}

Although HSP90 inhibitors offer promise for cancer cell treatment, resistance emerges early due to compensatory mechanisms involving activation of HSF1, which attenuates drug effectiveness [41]. Attenuation is associated with increased expression of HSP27, HSP70, and HSP90, mediating tumor cell survival and treatment resistance [22]. To elucidate whether our xanthone compound could sensitize cancer cells after treatment with the HSP90 inhibitors 17-AAG or radicicol, we first examined the expression of HSP27 after treatment with 17-AAG or radicicol. 17-AAG treatment for $36 \mathrm{hr}$ and radicicol treatment for $24 \mathrm{hr}$ dramatically increased the expression of HSP27 (Figure 3A). Cell death, cleaved casepase-3 and PARP cleavage data suggested that

A

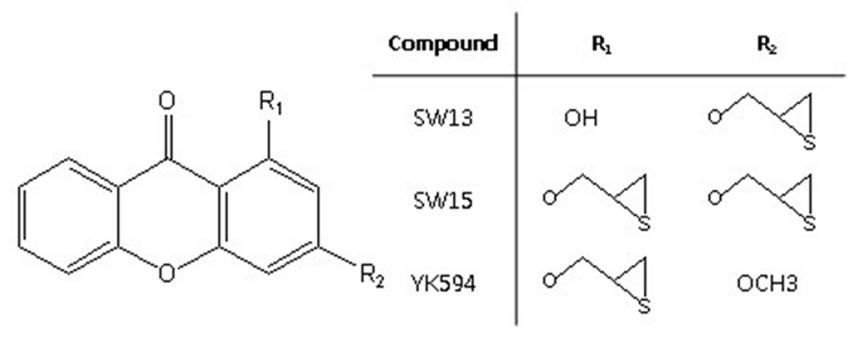

SW13: 1-hydrozy-3-(thiiran-2-ylmethyxy)-9H-xanthen-9-one SW15: 1,3-bis(thiiran-2-ylmethyxy)-9H-xanthen-9-one YK594: 1-methoxy-3-(thiiran-2-ylmethyxy)-9H-xanthen-9-one

B

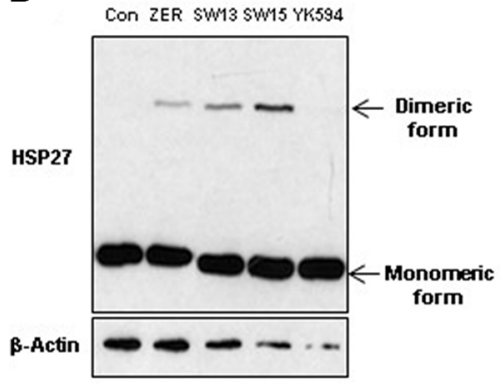

the combination of SW15 with $17-\mathrm{AAG}$ or radicicol synergistically sensitized the lung cancer cells and that the potency was more dominant for SW15 than ZER (Figure $3 \mathrm{~B}$ and $3 \mathrm{C}$ ). In vivo data using nude mice after grafting of NCI-H460 cells indicated that SW15 led to sensitization in combination with 17-AAG, but YK594, which did not induce any altered dimerization of HSP27, did not (Figure 4A). Increased expression of HSP27 was detected in 17-AAG treated tumor tissues when examined by both immunohistochemistry (Figure 4B, upper) and Western blotting (Figure 4B, bottom). Moreover, crosslinking of HSP27 was only observed in SW15 treated tumor tissues, but not YK594 treated ones (Figure 4B, bottom). Apoptotic and Ki-67-positive areas in tumor tissues also correlated well with the sensitizing effects of SW15 in combination with 17-AAG (Figure 4C, 4D, and Supplementary Figure S4). We also compared anticancer activity between SW15 and RP101, a small molecule HSP27 inhibitor which is under the phase II clinical trial [23] using lung cancer cells xenograft model and found that SW15 showed the anticancer activity in combination with 17-AAG (Supplementary Figure S5). From the data, we concluded that SW15-mediated cross-linking

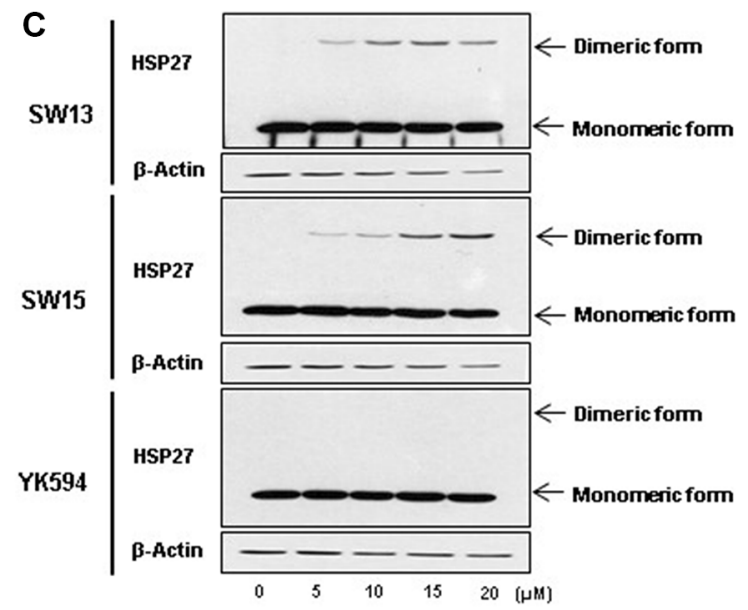

D

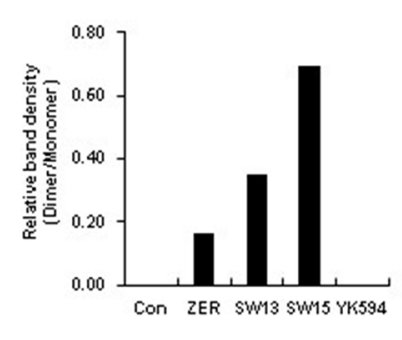

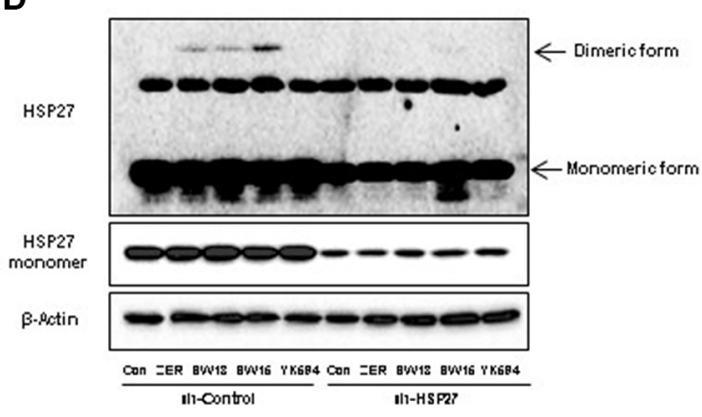

Figure 1: Xanthone structures led to different altered cross linking activity of HSP27. (A) Structures of xanthone compounds (SW13, SW15 and YK594). (B) Effects of the three xanthone compounds on altered cross-linking of HSP27. NCI-H460 cells were treated with each compound ( $12.5 \mu \mathrm{M}$ for $3 \mathrm{~h}$ ), and cell lysates were analyzed by Western blotting (left). Relative protein band intensity was calculated by comparing densitometric scans of the sample immunoblots with the values of control samples set at 1 (right). (C) NCI-H460 cells were treated with each compound $(0,5,10$, or $20 \mu \mathrm{M}$ for $12 \mathrm{~h}$ ), and cell lysates were analyzed by Western blotting. (D) NCI-H460 cells stably transfected with control (sh-Control) or shRNA of HSP27 (sh-HSP27) were treated with each compound (10 $\mu \mathrm{M}$ for $12 \mathrm{~h}$ ), and cell lysates were analyzed by Western blotting. Zerumbone (ZER, $10 \mu \mathrm{M})$ was used for a positive control. 
of HSP27 in combination with HSP90 inhibitors has a sensitization effects in lung cancer cells.

\section{The cysteine residue of HSP27 is important for sensitization of cancer cells by the xanthone compound in combination with HSP90 inhibitor}

To evaluate whether the synergistic effects of SW15 in combination with HSP90 inhibitors were derived from altered dimerization of the cysteine residue of HSP27, HSP27 knockdown cells and the mutant form of HSP25 at cysteine 141 residue (HSP25-C141A) were treated with 17-AAG and SW15. SW15-induced cross-linking of HSP27 was not seen in HSP27 knockdown cells, as well reduced sensitization effects, when it was detected

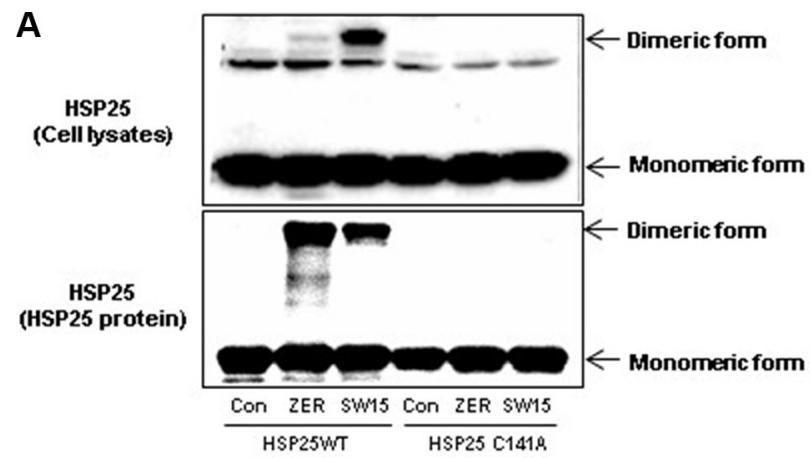

C
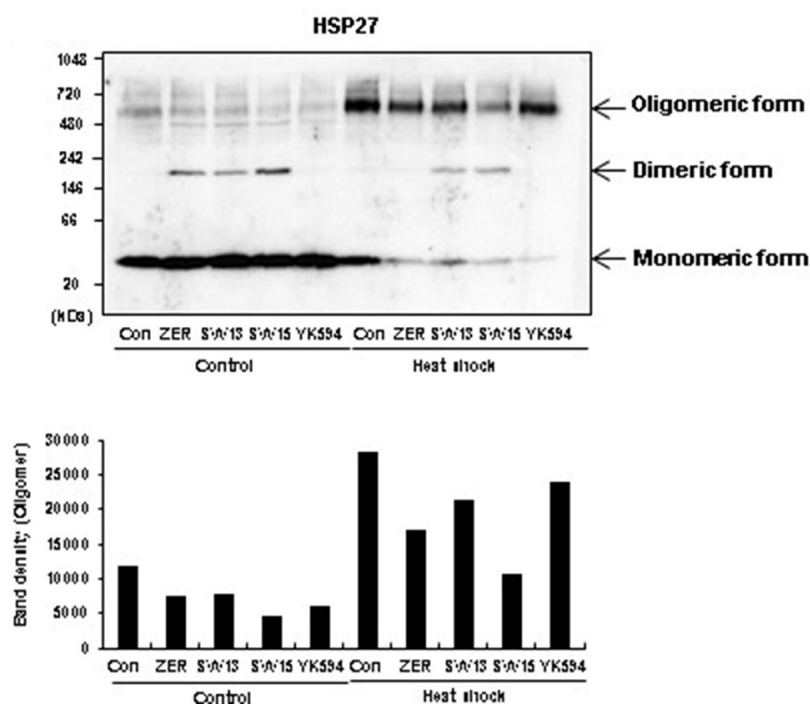

by cleaved PARP, cleaved caspase 3, and cell death (Figure 5A and 5C). Similarly, HSP25-C141A blocked SW15-mediated cross-linking (Figure 5B and 5D) accompanied by reduced sensitization (Figure 5D), providing further evidence that the cysteine residue of HSP27 is important for SW15-mediated altered crosslinking of HSP27 and sensitization effects in combination with 17-AAG.

\section{The xanthone compound sensitized cancer cells in combination with radiation}

Because, HSP27 overexpression showed reduced patient survival in lung adenocarcinoma, according to at least one publically available clinicogenomics database

B

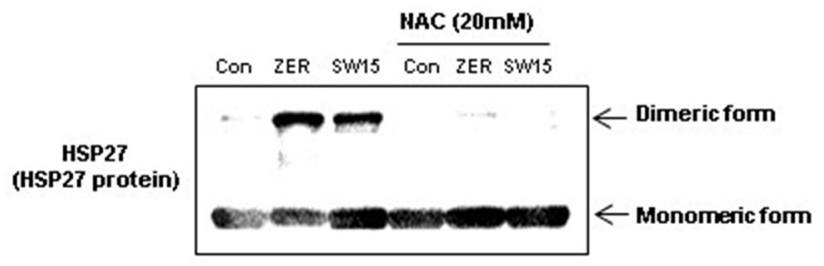

D

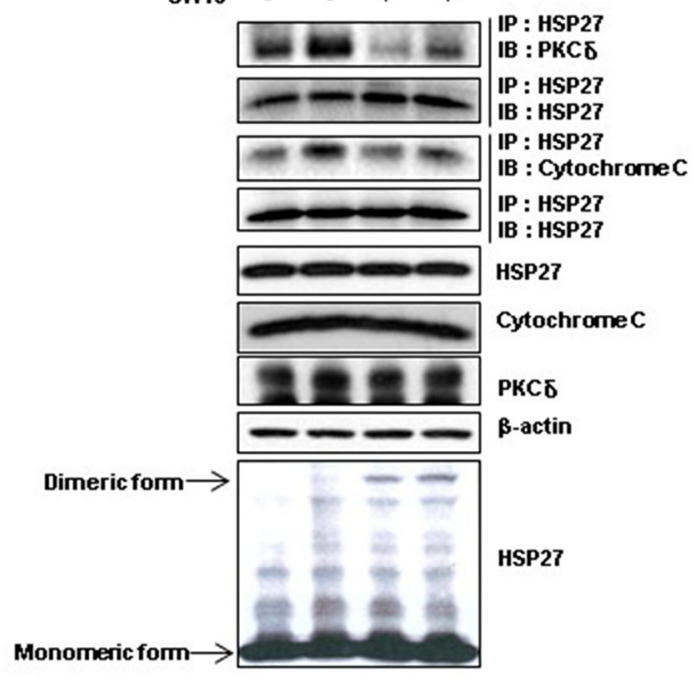

Figure 2: Altered cross linking by a xanthone compound occurred in the cysteine residue of HSP27 and inhibited HSP27 oligomerization. (A) NCI-H460 cells were transfected with wild type HSP25 (WT) or dimerization-deficient mutant HSP25 on the cysteine residue $(\mathrm{C} 141 \mathrm{~A})$ and cross-linking of the exogenous HSP25 was analyzed by SDS-PAGE (upper). Murine recombinant wild type HSP25 protein (WT) or dimerization-deficient mutant HSP25 protein (C141A) after treatment with the compounds $(0.5 \mathrm{mM}$ for $3 \mathrm{~h}$ ), was also analyzed by SDS-PAGE (bottom). (B) NCI-H460 cells were treated with DMSO, ZER, or SW15 (10 $\mu$ M) for $12 \mathrm{~h}$ with or without treatment with $20 \mathrm{mM} \mathrm{N}$-acetyl cysteine (NAC) and cross-linking of exogenous HSP25 was analyzed by SDS-PAGE. (C) NCI-H460 cells were treated with compounds (ZER, SW13, SW15 or YK594, 10 uM for $12 \mathrm{~h}$ ) with or without heat shock $\left(43^{\circ} \mathrm{C}\right.$ for 90 min, and further incubation at $37^{\circ} \mathrm{C}$ for 0 and $12 \mathrm{~h}$ ), and cross-linking of HSP27 was analyzed in non-reducing (without reducing agents and boiling) and reducing conditions (with reducing agents and boiling). Relative protein band intensity of oligomerized HSP27 was calculated by comparing densitometric scans of the sample immunoblots with the values of control samples set at 1 . Zerumbone (ZER, $10 \mu \mathrm{M})$ was used for a positive control. (D) NCI-H460 cells were treated with SW15 (10 $\mu \mathrm{M})$ with or without IR (10 Gy). After 12 h of irradiation, interactions of HSP27 with cytochrome c or PKCdelta were analyzed by immunoprecipitation (IP). 
(Figure 6A), we next examined whether altered crosslinking of HSP27 by SW15 affected HSP27-mediated resistance after treatment with conventional anticancer modalities. Pretreatment with SW15 for $3 \mathrm{hr}$ before IR decreased cell death as measured by MTT assay, and combined treatment of SW15 with IR significantly increased IR-induced cell death when examined at $24 \mathrm{hr}$ of IR (Figure 6B). In addition, cleavages of caspase 3 and PARP were synergistically increased $3 \mathrm{hr}$ after pretreatment with SW15 before IR when examined $24 \mathrm{hr}$ after IR (Figure 6C). In vivo data using nude mice after grafting of NCI-H460 cells indicated that SW15 showed the strongest radio-sensitization effect among the 3 compounds (SW13, SW15 and YK594) in combination with 5 Gy IR, even though the tumor regression effects of these 3 compounds alone without IR were similar (Supplementary Figure S6A). However, unlike SW15, treatment with YK594, which did not induce any altered cross-linking of HSP27, did not result in any sensitization to radiation in the xenografted mice (Figure 6D). Apoptotic and Ki-67-positive areas in tumor tissues also correlated well with the radio-sensitization effects of the three xanthone compounds (Figure 6E and Supplementary Figure S6B). From the data, we conclude that SW15mediated cross-linking of HSP27 is specific for HSP27 protein and has a radio-sensitization effect in cancer cells.

\section{The xanthone compound promoted sensitization to cancer cells in combination with the anticancer drugs}

To elucidate whether SW15-mediated sensitization by altered cross linking of HSP27 was a universal phenomenon, anticancer drugs taxol or cisplatin were
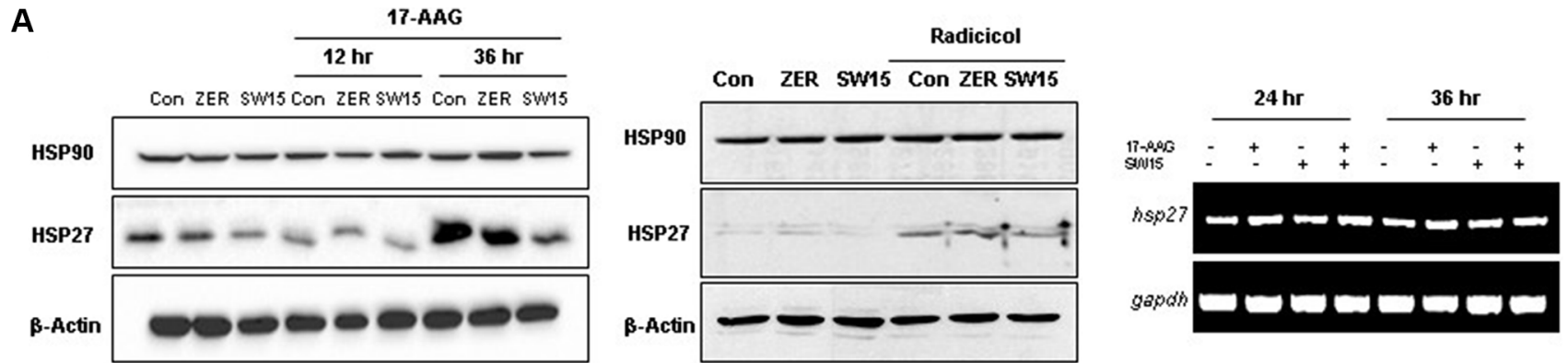

B
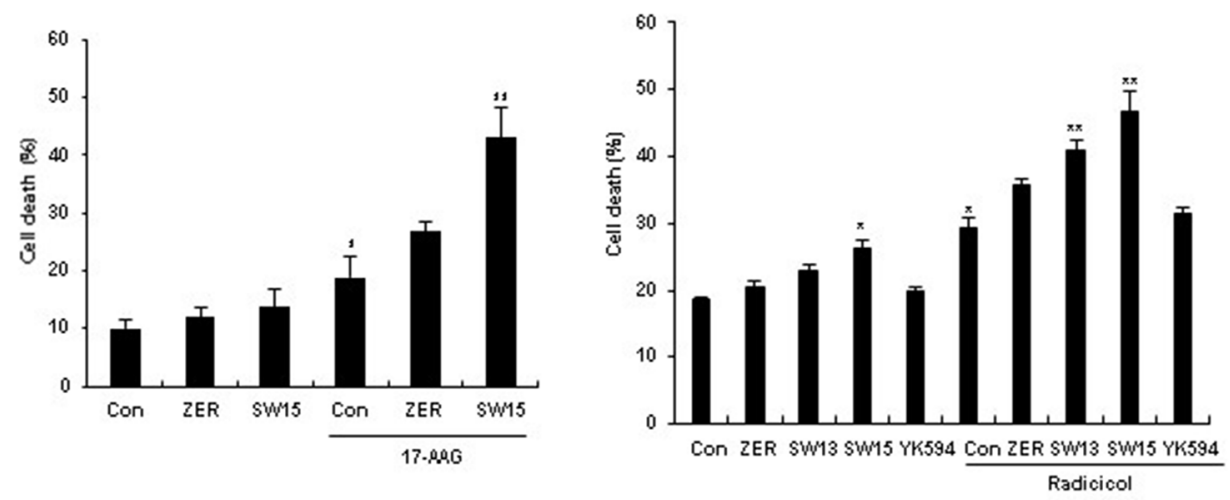

C
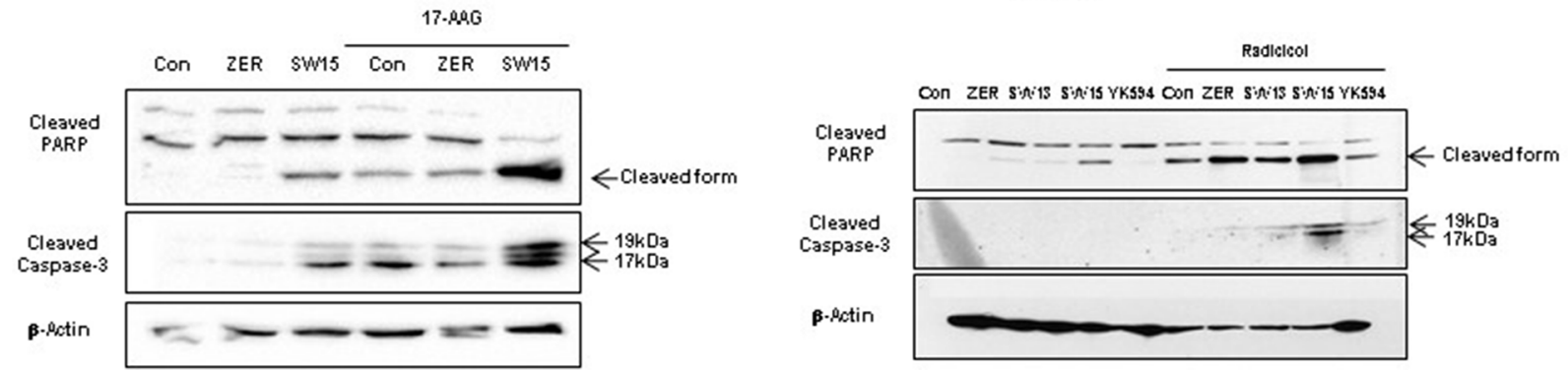

Figure 3: The xanthone compound induced sensitization to cancer cells in combination with HSP90 inhibitors. (A) NCI-H460 cells were treated with SW15, SW13, YK594 or ZER $(10 \mu \mathrm{M})$ for 12 and $36 \mathrm{~h}$, with or without 17-AAG (3 $\mu$ M) (left) or for $24 \mathrm{~h}$, with or without radicicol $(1 \mu \mathrm{M})$, Western blotting was performed (middle). RT-PCR was performed at 24 and $36 \mathrm{~h}$ after SW15 $(10 \mu \mathrm{M})$ treatment with or without 17-AAG $(3 \mu \mathrm{M})$ (right). Cell death was analyzed by flow cytometry after PI staining (B) and Western blot $(\mathbf{C})$ was performed at $24 \mathrm{~h}$ after 17-AAG or radicicol treatment. Results are the means and standard deviations of three independent experiments $\left({ }^{*} p<0.05\right.$ ver untreated control and $*^{*} p<0.05$ ver $17-\mathrm{AAG}$ or radiciol alone). Relative band intensity of the cleaved form of proteins was calculated by comparing densitometric scans of the sample immunoblots with the values of control samples set at 1 . 
combined with SW15. Cell viability, cleaved casepase-3 and PARP cleavage data suggested that combination of SW15 with cisplatin or taxol sensitized the lung cancer cells (Supplementary Figure S7 and Figure 7A). Moreover, cells with stably transfected shHSP27 with reduced SW15-mediated altered cross linking of HSP27 showed less sensitization to taxol or cisplatin in combination with SW15, when it was examined by cleaved PARP production (Figure 7B). Cell death as detected with PI staining also suggested that SW15 potentially increased cell death in combination with taxol or cisplatin in HSP27 overexpressed cells (Figure 7C).

\section{DISCUSSION}

The negative effect of HSP27 is the result of its ability to modulate key steps of the apoptotic cascade through interaction with crucial regulators such as
A

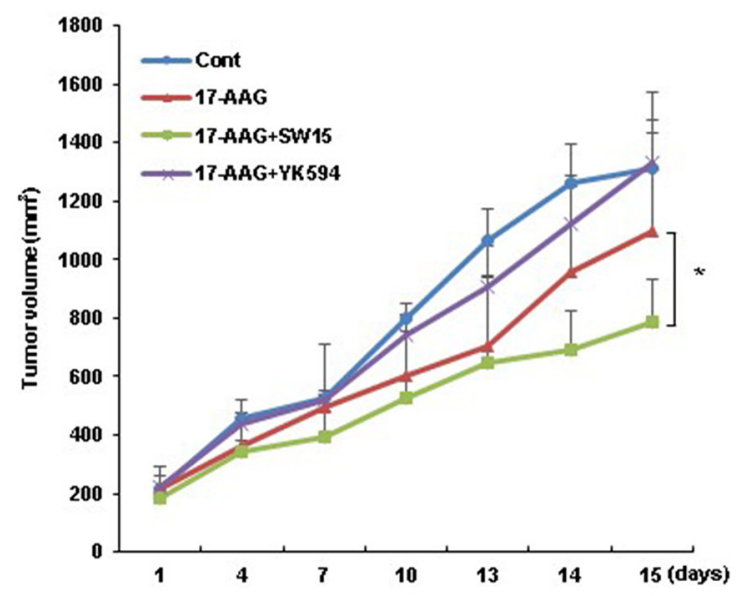

cytochrome c [24, 25], pro-caspase-3 [26, 27], DAXX [28], Akt [29], Stat3 [30], eIF4E [31], PKCdelta [17] and F-actin, an upstream modulator of apoptosis [18]. HSP27 is expressed in many cancers and is known to control resistance against treatment with cytotoxic drugs, development of metastases, and prevention of apoptosis [32]. Expression of HSP27 is upregulated in many cancer cells and is usually associated with a poor clinical outcome [33, 34, 19], making HSP27 a novel druggable target in cancer biology and its inhibition a new strategy in the development of innovative therapeutics [35]. These recent studies suggest the possibility of HSP27 inhibition as a molecular target for cancer therapy. However it is believed that, unlike other HSPs, small HSPs like HSP27 do not bind ATP, making HSP27 a difficult target for small compounds [36, 37].

We previously identified the new small molecule HSP27 inhibitor ZER, which displayed a novel mechanism
B

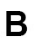

Con

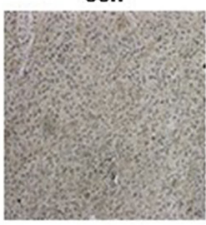

HSP27

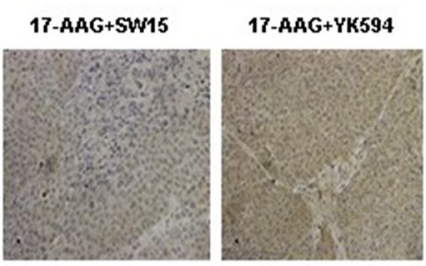

C

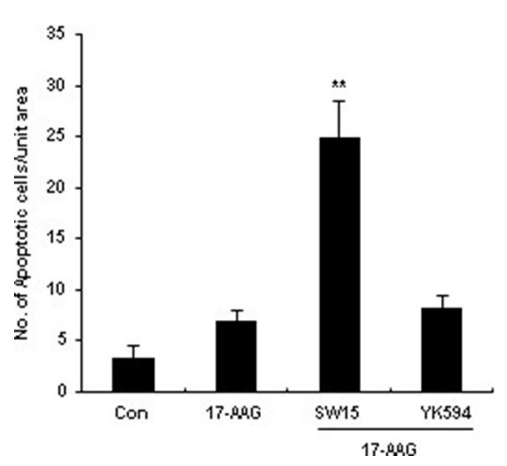

D

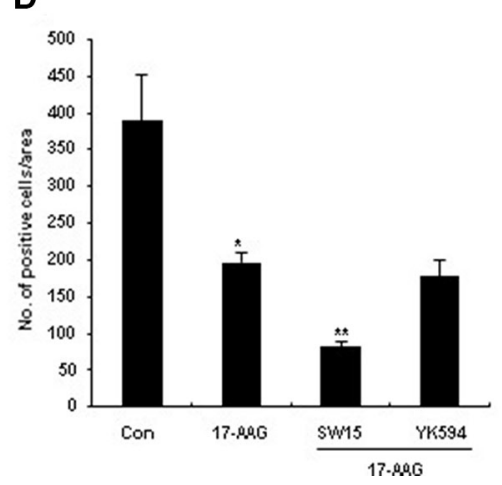

17-AAG

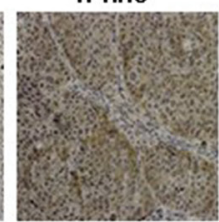

17-AAG+YK594

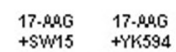

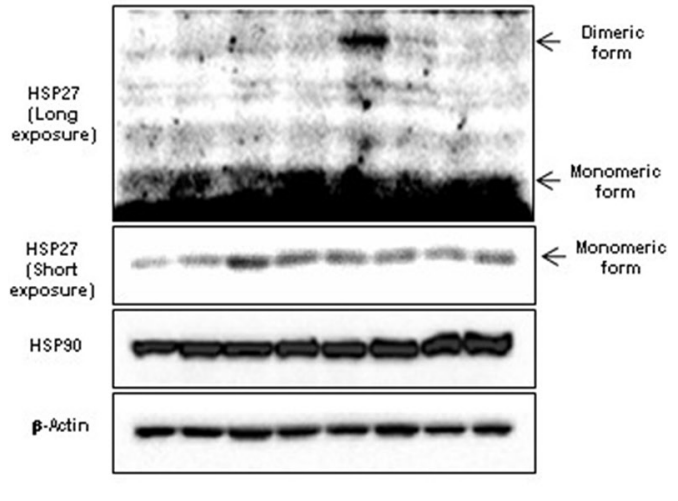

Figure 4: The xanthone compound showed synergistic regression effects to xenografted tumors in combination with HSP90 inhibitors. (A) NCI-H460 cells were injected subcutaneously into BALB/c nude mice ( $n=3 /$ group). Xenografted mice were treated 6 times with SW15 or YK594 $(6.8 \mathrm{mg} / \mathrm{kg}$ per each) delivered with a local regional application in combined with 6 times intraperitoneal treatment of 17-AAG $(25 \mathrm{mg} / \mathrm{kg})$. Tumor size was measured twice weekly. Results are the means and standard deviations $\left({ }^{*} p<0.05\right)$. TUNEL staining $(\mathbf{C})$ and Ki-67 staining (D) were performed using tumor tissues. Graph represents mean and standard deviation $(* p<0.05 v s$ untreated control group and $* * p<0.05 v s$ 17-AAG alone treated group). (B) NCI-H460 xenografted nude mice (each group had 2 mice) were treated three times every 2 days with SW15 or YK594 (6.8 mg/kg per each) with or without 17-AAG (25 mg/kg). Three hours after the last treatment, tumor tissues were extracted, and immunohistochemistry for HSP27 was performed (upper). Western blotting analysis for HSP27, HSP90, and $\beta$-Actin was also performed (bottom). 
of altered cross- linking of HSP27, and induced cancer sensitization in combination with IR [21]. In this study, we identified an even stronger cross linker of HSP27, a xanthone compound (SW15), which also yielded greater sensitizing effects than ZER in combination with IR. However, the same xanthone compound with a different side chain (YK594), did not induce any altered cross linking of HSP27 and did not show any sensitization effects, suggesting that some critical structures for insertion to the cysteine residue of HSP27 may be present. In the case of ZER, the unsaturated carbonyl group is important for insertion to the cysteine residue of HSP27 [21], however, all unsaturated carbonyl groups did not consistently induce altered cross linking of HSP27 (data not shown). Because the complete structure of HSP27 is not available, more detailed experiments are necessary to fully elucidate the interaction between small molecules and HSP27.
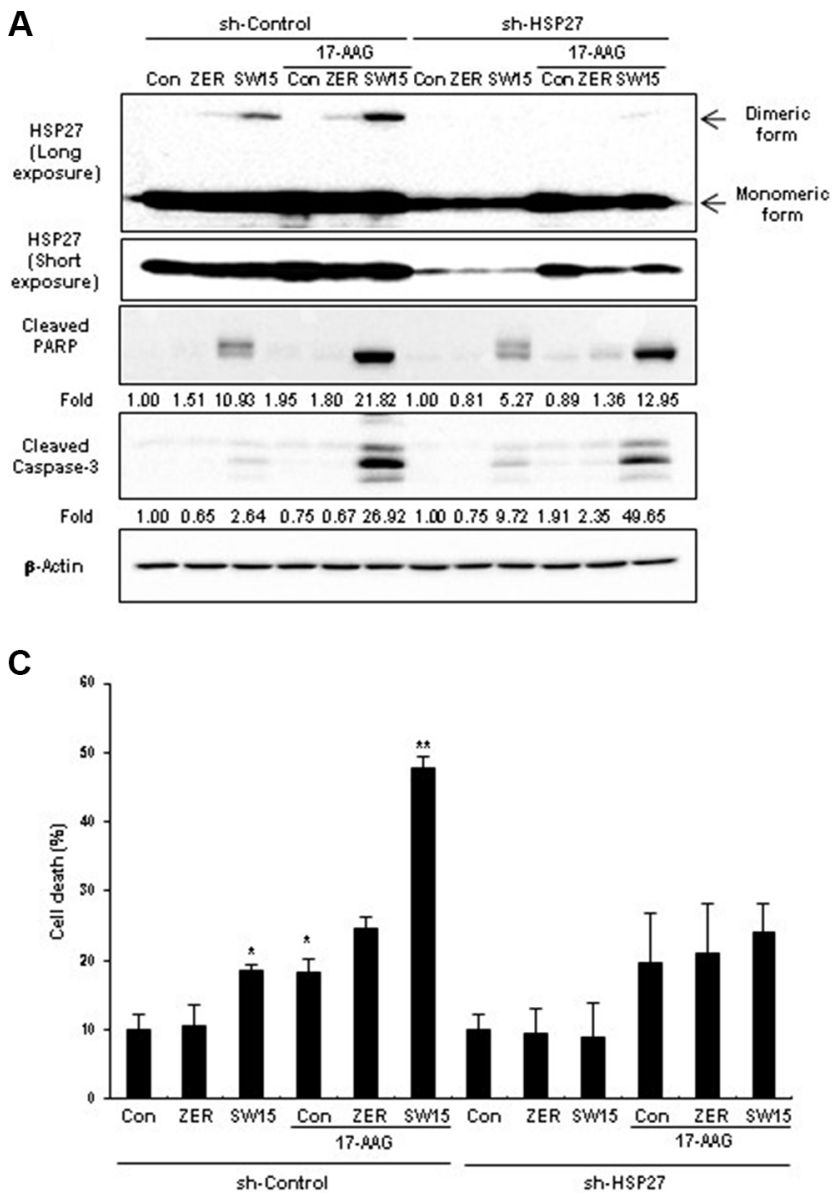

Cys 141 (the normal dimer site for mouse HSP25, cysteine 137 for human HSP27) is thought to be important for altered cross linking by SW15, and treatment with NAC blocked altered cross linking activity of SW15, providing evidence for a close relationship. In this study, a protein with a molecular weight of approximately $50 \mathrm{kDa}$ was observed after SW15 treatment. Unlike to ZER, we did not detect insertion of complete SW15 structure to cross linked dimer form of HSP27 by mass spectrophotometry, suggesting that chemical changes were made to SW15 for HSP27 cross- linking. When the binding activity of HSP27 with apoptotic molecules was examined after treatment with SW15, increased binding activity between HSP27 and cytochrome c or PKCdelta after IR was inhibited by SW15 treatment. Moreover, cross-linking of HSP27 by SW15 was specific for HSP27 protein, because cross-linking activity of other proteins

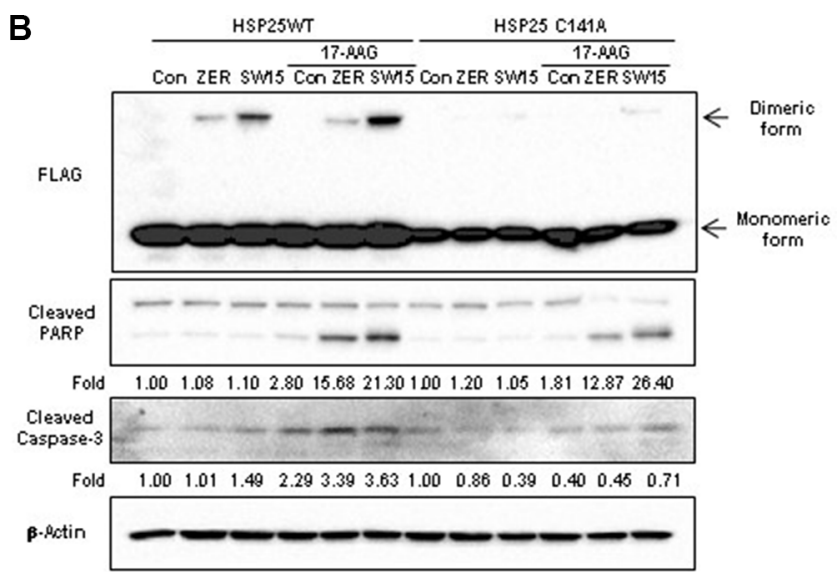

D

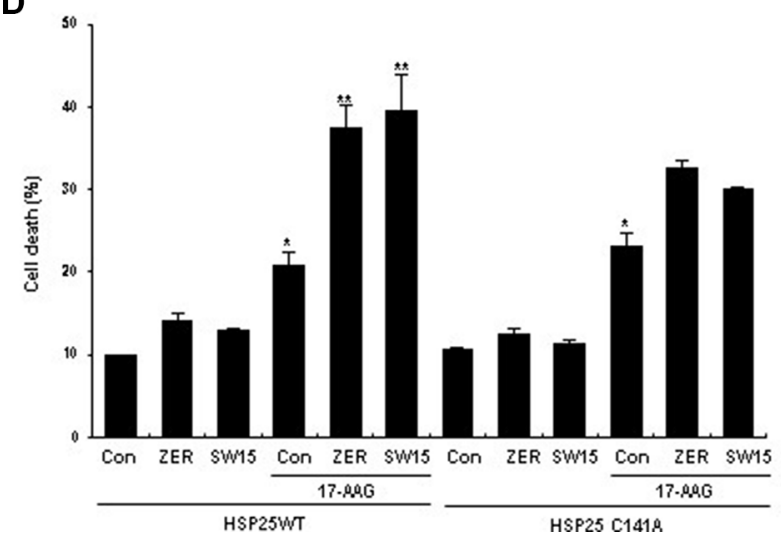

Figure 5: Altered cross linking of HSP27 by a xanthone compound was important for sensitization of cancer cells in combination with an HSP90 inhibitor. (A) NCI-H460 cells stably transfected with control (sh-Control) or shRNA of HSP27 (shHSP27) were treated with SW15 (10 $\mathrm{M}$ for $3 \mathrm{~h})$, and cell lysates were analyzed by Western blotting. Relative protein band intensity of oligomerized HSP27 was calculated by comparing densitometric scans of the sample immunoblots with the values of control samples set at 1 and expressed as a fold increase. (B) NCI-H460 cells were transfected with wild type HSP25 (WT) or dimerization-deficient mutant HSP25 (C141A) and cell lysates were analyzed by SDS-PAGE. Relative protein band intensity of oligomerized HSP27 was calculated by comparing densitometric scans of the sample immunoblots with the values of control samples set at 1 and expressed as a fold increase. (C), (D) NCI-H460 cells were treated with ZER or SW15 $(10 \mu \mathrm{M})$ for $24 \mathrm{~h}$, and then cell death was analyzed by flow cytometry after PI staining $\left({ }^{*} p<0.05 v s\right.$ untreated control cells and $* * p<0.05 v s$ corresponding $17-A A G$ alone treated cells). Zerumbone $(Z E R, 10 \mu M)$ was used for a positive control. 
that have cysteine residues and form disulfide bonds such as HSP90, HSP70, NFkB, JNK2, Akt1, and $\beta$-Actin, did not induce cross-linked dimer forms by SW15. From the data, we conclude that SW15-mediated cross-linking of HSP27, which is specific for HSP27 protein, may yield a functionally defective form.

HSP90 interacts with several proteins involved in growth factor receptors, cell cycle regulators, and signaling kinases, including protein kinase $\mathrm{B}$ (Akt) or androgen receptor (AR) [39, 40]. Tumor cells express higher HSP90 levels and activity than benign cells [41, 42], and HSP90 inhibition has emerged as a target in cancers. However, HSP90 inhibitors may cause compensatory mechanisms, such as the activation of HSP27 [9]. Therefore, treatment combining an HSP90 inhibitor and an HSP27 inhibitor might be an attractive therapeutic strategy. Indeed, SW15 inhibited HSP27 expression due to altered cross-linking activity after treatment of HSP90 inhibitor. Moreover, combined treatment of HSP90 inhibitor and SW15 synergistically enhanced cancer cell death in vitro and in vivo, depending on HSP27 expression and the presence of the normal dimerization site at Cys141, suggesting that addition of an HSP27 inhibitor with altered cross linking of HSP27 could overcome HSP90 inhibitor-mediated compensatory mechanisms such as increased expression of HSP27.

Cytotoxic anticancer modalities such as IR, taxol and cisplatin are also involved in HSP27-mediated resistance [43-46], making an HSP27 cross linker a useful strategy for sensitization of cancer cells. Indeed, our results indicated that SW15 in combination with IR, taxol or cisplatin synergistically induced sensitization of lung
A

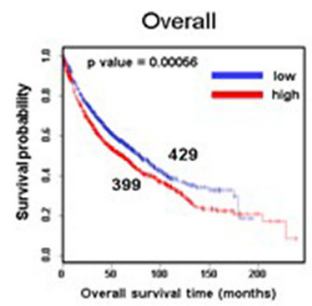

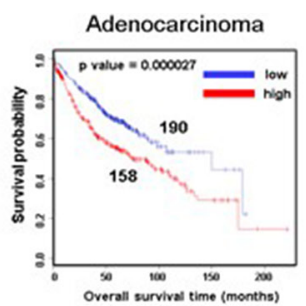

C

B

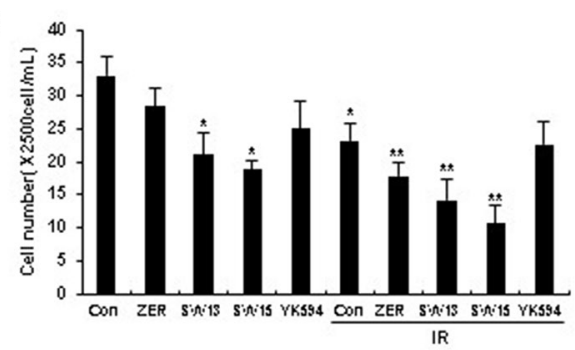

D

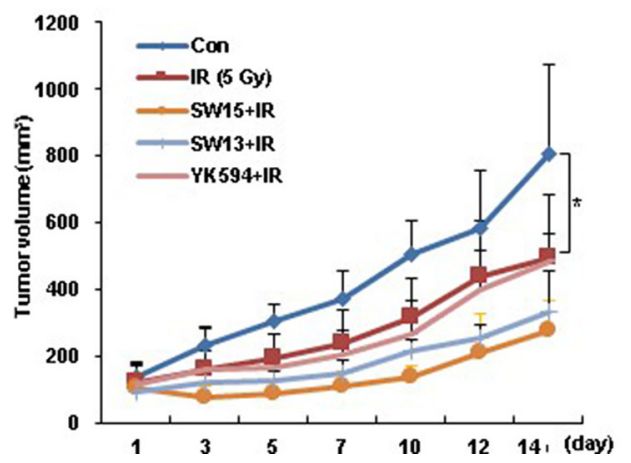

E
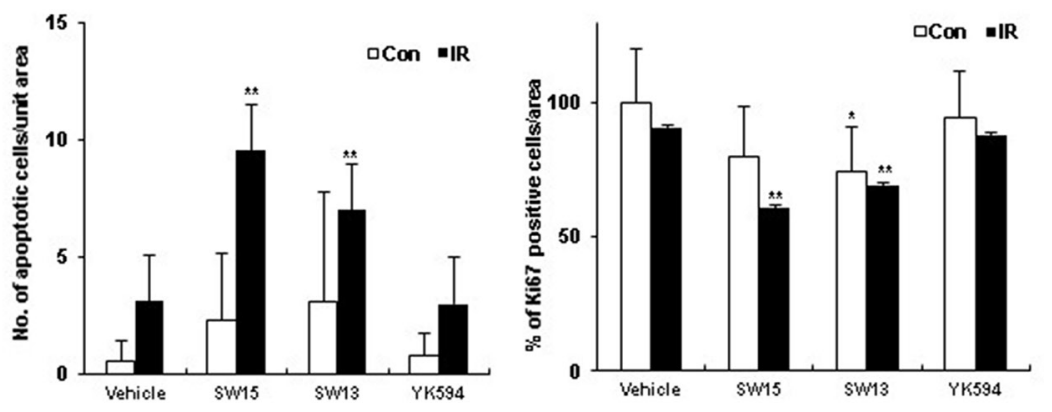

Figure 6: The xanthone compound induced radiosensitization. (A) Kaplan-Meier (KM) plot for hsp27 gene in overall lung cancer patients (including adenocarcinoma and squamous cell carcinoma patients) and lung adenocarcinoma patients was shown with $p$ value. (B) NCI-H460 cells were treated with ZER, SW13, SW15, and YK594 (10 $\mu$ M) with or without IR (3 Gy). After 24 h of irradiation, cell survival was counted using trypan-blue. Results are the means and standard deviations of three independent experiments $\left({ }^{*} p<0.05\right.$ $v s$ untreated control cells and $* * p<0.05$ vs IR alone treated cells). (C) Cleavage of PARP and Caspase-3 was analyzed by Western blot. Relative band intensity of the cleaved form of proteins was calculated by comparing densitometric scans of the sample immunoblots with the values of control samples set at 1 and expressed as a fold increase. Zerumbone (ZER, $10 \mu \mathrm{M})$ was used for a positive control. (D) NCI-H460 cells were injected subcutaneously into BALB/c nude mice ( $n=3$ /group). After 5 Gy irradiation, xenografted mice were treated 6 times with SW15, SW13 or YK594 $(6.8 \mathrm{mg} / \mathrm{kg})$ delivered with a local regional application. Tumor size was measured twice weekly. Results are the means and standard deviations $\left({ }^{*} p<0.05\right.$ ). (E) TUNEL staining (left) and Ki-67 staining (right) were performed using tumor tissues. Graph represents mean and standard deviation $\left({ }^{*} p<0.05\right.$ vs untreated control group and ** $p<0.05$ vs IR alone group). 
cancer cells, suggesting that SW15 might be a universal sensitizer to combat HSP27-mediated resistance.

The treatment of SW15 alone did not show any strong cytotoxicity in vitro assay, however, in vivo data revealed that antitutmor activity of SW15 is similar to the effects of 5 Gy IR, which may give a stronger rationale to SW15 as a candidate of anticancer drug.

In conclusion, since HSP27 expression correlates well with poor survival of lung tumor patients, especially those with lung adenocarcinoma, inhibition of HSP27 represents a good strategy for sensitization of cancer cells in combination with conventional anticancer modalities. Small molecules such as ZER and SW15, which promote altered cross linking of HSP27, offer a promising approach for inhibition of HSP27, although further research is needed to evaluate the safety and efficacy of both compounds in a clinical setting.

\section{MATERIALS AND METHODS}

\section{Compounds and chemicals}

SW13, SW15, and YK594 were synthesized as described in Supplementary information. zerumbone (ZER), was isolated and purified from the dried rhizomes of Zimgiber zerumbet Smith (18). Tanespimycin (17-allylamino-17-demethoxygeldanamycin, 17-AAG) (Selleckch em, S1141) and radicicol (Sigma Aldrich, R2146) was dissolved in DMSO and diluted to $10 \mathrm{mM}$ with tissue culture medium immediately prior to use. Cisplatin, N-aceylcystein (NAC) was purchased from Sigma Aldrich and dissolved in PBS as a $5 \mathrm{mM}$ stock. Taxol was purchased from Santa Cruz Biotechnology (Santa Cruz, CA, USA) (sc-201439A).

\section{Cell culture and transfection}

The human non-small lung cancer cell line NCI-H460 was cultured in RPMI (Gibco, Gaithersburg, MD, USA) supplemented with $10 \%$ fetal bovine serum (Gibco) in a $37^{\circ} \mathrm{C}$ incubator with $5 \% \mathrm{CO}_{2}$. Transfections were performed using Lipofectamine 2000 (Invitrogen, Carlsbad, CA USA). Lentiviruses were used to create stable NCI-H460 cell lines expressing shRNA for HSP27 (puromycin resistance gene). The HSP27 shRNA plasmid (sc-29350-SH), and shRNA plasmid transfection reagent (sc-108061) were ordered from Santa Cruz Biotechnology. To generate the sh-Control, and sh-HSP27 cells, the cell lines were transduced with $1 \mathrm{~mol}$ of lentivirus and selected using puromycin $(1 \mathrm{ug} / \mathrm{mL})$ for at least one week.
A

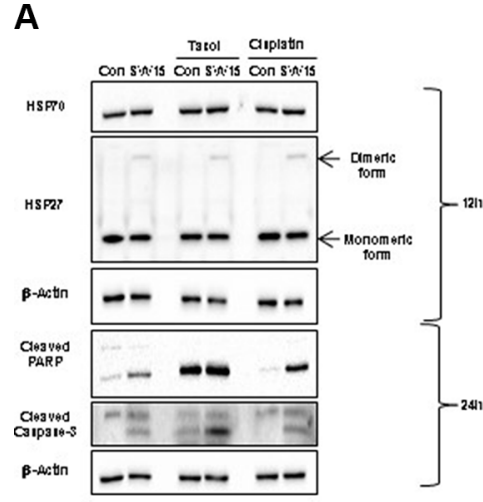

B

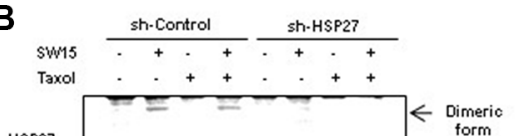

12110

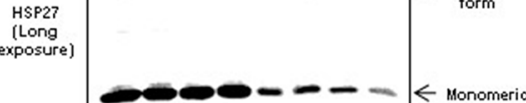

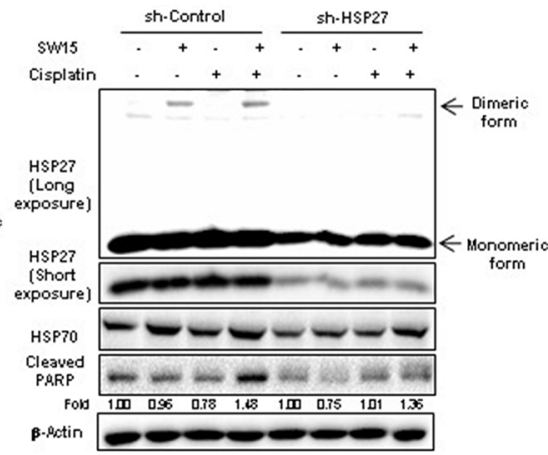

C

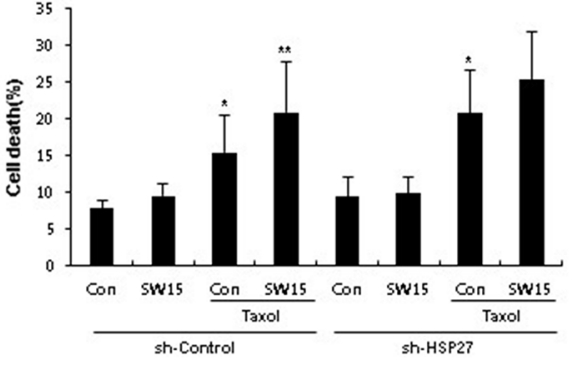

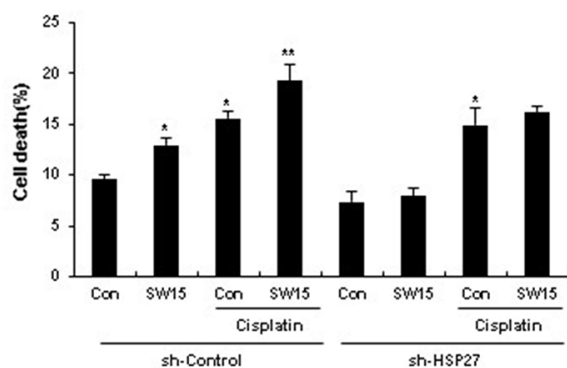

Figure 7: The xanthone compound induced sensitization to cancer cells in combination with conventional anticancer drugs. (A) NCI-H460 cells were treated with SW15 $(10 \mu \mathrm{M})$ for 12 and $24 \mathrm{~h}$, with or without cisplatin $(3 \mu \mathrm{M})$ or Taxol $(0.01 \mu \mathrm{M})$, and Western blotting was performed. (B) NCI-H460 cells stably transfected with control (sh-Control) and shRNA of HSP27 (sh-HSP27) were treated with SW15 $(10 \mu \mathrm{M})$ for $12 \mathrm{~h}$, with or without cisplatin $(20 \mu \mathrm{M})$ or Taxol $(0.005 \mu \mathrm{M})$, and cell lysates were analyzed by Western blotting. Relative band intensity of the cleaved form of proteins was calculated by comparing densitometric scans of the sample immunoblots with the values of control samples set at 1 and expressed as a fold increase. (C) Cell death was analyzed by flow cytometry after propidium iodide (PI) staining. Results are the means and standard deviations of three independent experiments $\left({ }^{*} p<0.05 v s\right.$ untreated control cells and ${ }^{* *} p<0.05 v s$ corresponding taxol or cisplatin alone treated cells). 


\section{DNA constructs and antibodies}

Wildtype (WT) mouse HSP25 (GenBank accession number, NM_013560.2) was polymerase chain reaction (PCR)-amplified, and the dimerization mutant HSP25 (C141A) was constructed by overlap extension PCR. The PCR fragments were digested with BamHI-EcoRI and ligated into p3x-Flag-MycCMV-26, yielding p3x-flag-HSP25 (WT) and p3x-flagHSP25 (C141A). WT and dimerization mutant (C141A) HSP25 were cloned into p3x-Flag-myc-cmv-26 expression vector [21]. Goat polyclonal anti-HSP27 (sc-1049), goat polyclonal anti-HSP70 (sc-1060), mouse monoclonal anti-HSP90 $\alpha / \beta$ (sc-13119), mouse monoclonal anti-HSF1 (sc-17757), rabbit-polyclonal anti-PKC $\delta$ (sc-213) and mouse monoclonal anti- $\beta$-actin (sc-47778) antibodies were purchased from Santa Cruz Biotechnology. Rabbit polyclonal anti-cleaved caspase-3 (\#9661), rabbit polyclonal anti-cleaved PARP (\#9541), and rabbit polyclonal anti-cleaved cytochrome c (\#9661) antibodies were purchased from Cell Signaling (Beverly, MA, USA). Mouse monoclonal anti-cytochrome c (\#556432, BD Biosciences) and rabbit polyclonal antiPARP (\#9542, Cell signaling) antibodies were used for immuneprecipitation. Mouse-monoclonal anti-HSP27 (ADI-SPA-800, Enzo) antibody was also used for immunohistochemistry.

\section{Polyacrylamide gel electrophoresis and Western blot}

For polyacrylamide gel electrophoresis (PAGE) and Western blot (WB) analysis, cells were lysed with RIPA (Radio immunoprecipitation assay) buffer (20 mM Tris- $\mathrm{HCl}$ [pH 7.5], $150 \mathrm{mM} \mathrm{NaCl}, 1 \mathrm{mM}$ EDTA (ethylenediamine tetraacetic acid), $1 \% \mathrm{NP}-40,1 \%$ sodium deoxycholate, $1 \mathrm{mM}$ glycerophosphate, $1 \mathrm{mM} \mathrm{Na}_{3} \mathrm{VO}_{4}$, $4 \mathrm{mM} \mathrm{NaF}$ ) supplemented with protease inhibitor cocktail (Calbiochem, La Jolla, CA, USA). The samples were boiled for $5 \mathrm{~min}$, and an equal amount of protein was analyzed on SDS-PAGE. For non-reducing SDS-PAGE, the reducing agents Dithiothreitol and $\beta$-mercaptoethanol were omitted from the samples and directly loaded onto gels without boiling.

\section{Immunoprecipitation}

For immunoprecipitation experiments, cells were lysed in immunoprecipitation buffer $(20 \mathrm{mM}$ Tris- $\mathrm{HCl}$ [pH 7.5], $150 \mathrm{mM} \mathrm{NaCl}, 1 \mathrm{mM}$ EDTA (ethylenediamine tetraacetic acid), $1 \%$ NP-40, $1 \%$ sodium deoxycholate, $1 \mathrm{mM}$ glycerophosphate, $1 \mathrm{mM} \mathrm{Na} \mathrm{VO}_{4}, 4 \mathrm{mM} \mathrm{NaF}$ ). After lysates were centrifuged ( $30 \mathrm{~min}$ at $15,814 \times \mathrm{g}$ ) to remove particulate material, the supernatant was incubated with primary antibodies with gentle rocking overnight at $4^{\circ} \mathrm{C}$. The immunocomplexes were precipitated with protein A agarose beads and incubated at $4^{\circ} \mathrm{C}$. After 90 $\mathrm{min}$, the samples were analyzed by immunoblotting.

\section{Irradiation}

Cells were exposed to $\gamma$-rays with a ${ }^{137} \mathrm{Cs} \gamma$-ray source (MDS Nordion, Ottawa, Canada) with a dose rate of $2.34 \mathrm{~Gy} / \mathrm{min}$.

\section{Identification of protein band}

p3x-Flag-myc-cmv-26 vector was used to express a Flag tag and the full sequence of mouse HSP25. NCI-H460 cells were transfected with the p3x-flagHSP25 (WT) and p3x-flag-HSP25 (C141A) and treated with ZER $(10 \mu \mathrm{M})$ for $12 \mathrm{~h}$. Cell lysates were separated by SDS-PAGE. Untreated cells were also used as a control. To estimate the location of a band, a Coomassie Brilliant Blue R-250-stained gel was compared by Western blot analysis. Protein bands were excised and digested with trypsin. The digests were analyzed by quadrupole timeof-flight (Q-TOF).

\section{MTT analysis}

Cell viability was evaluated using MTT assay. For MTT assay, cells $\left(1.5 \times 10^{5}\right.$ cells $\left./ \mathrm{ml}\right)$ were seeded in 96well plates (Corning Inc., NY, USA) overnight and treated SW15 $(10 \mu \mathrm{M})$, taxol $(0.01 \mu \mathrm{M})$ or cisplatin $(5 \mu \mathrm{M})$ for $24 \mathrm{~h}$ at $37^{\circ} \mathrm{C}$. After treatment, the cell viability was determined by adding $10 \mu \mathrm{l}$ MTT solution $(5 \mathrm{mg} / \mathrm{ml}$ in PBS) to each well followed by incubation for $4 \mathrm{~h}$ at $37^{\circ} \mathrm{C}$ with $5 \% \mathrm{CO}_{2}$. The MTT mixture was removed and $150 \mu \mathrm{l}$ DMSO was added to each well. Samples were agitated on a shaker for $30 \mathrm{~min}$, and the absorbance at $540 \mathrm{~nm}$ was recorded using a micro-plate reader (Bio-Tek, ELX800, USA). Cell viability was calculated as follows: (1average absorbance of treated group/average absorbance of control group) $\times 100 \%$.

\section{Flow cytometry analysis}

The cells were washed twice with $1 \times$ phosphatebuffered saline (PBS) and incubated in the dark for $10 \mathrm{~min}$ at $37^{\circ} \mathrm{C}$ in PBS containing $10 \mu \mathrm{g} / \mathrm{ml}$ propidium iodide (Sigma Aldrich). Flow cytometric analysis was performed using a FACScan flow cytometer (Becton Dickinson, Franklin Lakes, NJ, USA).

\section{Real time PCR (RT-PCR)}

Total RNA was extracted using QIAzol (QIAGEN). cDNA was synthesized using the ReverTra Ace RT-PCR kit (Toyobo, Osaka, Japan). The transcript levels of hsp27, and $h s p 70$ were measured by RT-PCR (GenDEPOT, Barker, TX, USA). gapdh was used as an internal control gene. 


\section{Tumor xenografts in nude mice}

A single NCI-H460 cell suspension $\left(1 \times 10^{6}\right.$ cells $)$ was injected subcutaneously into the hind legs of 6-weekold $\mathrm{BALB} / \mathrm{c}$ athymic nude mice (SLC, Hamamatsu, Japan). The volume injected was $50 \mu \mathrm{l}$ per mouse to avoid leakage, and a different site was used for each injection. When the tumor reached a minimal volume of $100-300 \mathrm{~mm}^{3}$, xenografted mice were treated 6 times with SW15, SW13, or YK594 $(6.8 \mathrm{mg} / \mathrm{kg})$ with or without treatment of local regional application of 17-AAG $(25 \mathrm{mg} /$ $\mathrm{kg}$ ) or of treatment of IR ( $5 \mathrm{~Gy}$ ) on the whole body. Tumor volumes were determined according to the formula $\left(\mathrm{L} \times \mathrm{W}^{2}\right) / 2$, by measuring tumor length $(\mathrm{L})$ and width $(\mathrm{W})$ with a caliper. Tumors were measured twice weekly and allowed to grow for 3 weeks.

\section{TUNEL assay}

For the TUNEL assay, the Peroxidase In Situ Apoptosis Detection Kit was used according to the manufacturer's recommendations. The number of TUNEL-positive tumor cells and the total number of tumor cells were measured in three microscopic fields of randomly selected tumors and then the mean value was calculated as the percentage of TUNEL-positive tumor cells.

\section{Immunohistochemistry}

Immunohistochemistry was performed on sections of paraffin-embedded specimens using monoclonal antiKi-67 antibody (Dako, M7240) or monoclonal anti-HSP27 antibody (Santa Cruz Biotechnology, sc-13132). Briefly, after deparaffinization and hydration, the sections were treated with heat-mediated antigen retrieval using $10 \mathrm{mM}$ citrate buffer ( $\mathrm{pH} \mathrm{6.0)}$ for $30 \mathrm{~min}$. Then the endogenous peroxidase activity was quenched by $3 \%$ hydrogen peroxide solution for $10 \mathrm{~min}$. Non-specific binding was prevented by incubation with 5\% normal goat serum for 1 $\mathrm{h}$ at $37^{\circ} \mathrm{C}$. After that, the sections were incubated with antiHSP27 antibody (1:250 dilutions) or anti-Ki-67 antibody (1:150 dilutions) as the primary antibody overnight at $4^{\circ} \mathrm{C}$ in a moist chamber. Secondary antibody incubation and staining were performed using the EnVision ${ }^{\circledR}+$ SystemHRP (ABC) kit (Vector Laboratories, Burlingame, CA, USA) according to the manufacturer's recommendations and observed using light microscopy (Carl Zeiss Axio Scope, A1).

\section{Survival analysis}

Survival analyses were performed with on-line survival analysis (www.kmplot.com).

\section{Statistical analysis}

Values are displayed as mean plus or minus SEM. Comparisons between groups were carried out by the one-way ANOVA for experiments with more than three subgroups. Post hoc range tests were performed with the one-way ANOVA. Results were considered statistically significant for $P$ values less than 0.05 .

\section{ACKNOWLEDGMENTS}

This work was supported by a grant of the Nuclear R\&D Program (2011-0031696, 2013M2A2 A704043384, and 2015M2A2A7A 03044831) and the Bio \& Medical Technology Development Program (NRF2014M3A9A9073 908) of the National Research Foundation of Korea (NRF), funded by the Korean government (Ministry of Science, ICT \& Future Planning).

\section{CONFLICTS OF INTEREST}

None.

\section{REFERENCES}

1. Zoubeidi A, Chi K, Gleave M. Targeting the cytoprotective chaperone, clusterin, for treatment of advanced cancer. Clin Cancer Res. 2010; 16:1088-93.

2. Kumano M, Furukawa J, Shiota M, Zardan A, Zhang F, Beraldi E, Wiedmann RM, Fazli L, Zoubeidi A, Gleave ME. Cotargeting stress-activated Hsp27 and autophagy as a combinatorial strategy to amplify endoplasmic reticular stress in prostate cancer. Mol Cancer Ther. 2012; 11:1661-71.

3. Shiota M, Bishop JL, Nip KM, Zardan A, Takeuchi A, Cordonnier T, Beraldi E, Bazov J, Fazli L, Chi K, Gleave M, Zoubeidi A. Hsp27 regulates epithelial mesenchymal transition, metastasis, and circulating tumor cells in prostate cancer. Cancer Res. 2013; 73:3109-19.

4. Ischia J, So AI. The role of heat shock proteins in bladder cancer. Nat Rev Urol. 2013; 10:386-95.

5. Hadchity E, Aloy MT, Paulin C, Armandy E, Watkin E, Rousson R, Gleave M, Chapet O, Rodriguez-Lafrasse C. Heat shock protein 27 as a new therapeutic target for radiation sensitization of head and neck squamous cell carcinoma. Mol Ther. 2009; 17:1387-94.

6. Hayashi N, Peacock JW, Beraldi E, Zoubeidi A, Gleave ME, Ong CJ. Hsp27 silencing coordinately inhibits proliferation and promotes Fas-induced apoptosis by regulating the PEA15 molecular switch. Cell Death Differ. 2012; 19:990-1002.

7. Lamoureux F, Thomas C, Yin MJ, Fazli L, Zoubeidi A, Gleave ME. Suppression of heat shock protein 27 using OGX-427 induces endoplasmic reticulum stress and 
potentiates heat shock protein 90 inhibitors to delay castrateresistant prostate cancer. Eur Urol. 2014; 66:145-55.

8. Lamoureux F, Thomas C, Yin MJ, Kuruma H, Beraldi E, Fazli L, Zoubeidi A, Gleave ME. Clusterin inhibition using OGX-011 synergistically enhances Hsp90 inhibitor activity by suppressing the heat shock response in castrate-resistant prostate cancer. Cancer Res. 2011; 71:5838-49.

9. Xia Y, Liu Y, Wan J, Wang M, Rocchi P, Qu F, Iovanna JL, Peng L. Novel triazole ribonucleoside down-regulates heat shock protein 27 and induces potent anticancer activity on drug-resistant pancreatic cancer. J Med Chem. 2009; 52:6083-96.

10. Xia Y, Liu Y, Rocchi P, Wang M, Fan Y, Qu F, Iovanna JL, Peng L. Targeting heat shock factor 1 with a triazole nucleoside analog to elicit potent anticancer activity on drug-resistant pancreatic cancer. Cancer Lett. 2012; 318:145-53.

11. Stetler RA, Gao Y, Signore AP, Cao G, Chen J. HSP27: mechanisms of cellular protection against neuronal injury. Curr Mol Med. 2009; 9:863-72.

12. Jin YB, Seo WD, Lee YJ, Lee YS. Toxicological evaluation of zerumbone on antitumor effects in mice. Afr J Pharm Pharmacol. 2013; 7:466-473.

13. Rocchi P, Jugpal P, So A, Sinneman S, Ettinger S, Fazli L, Nelson C, Gleave M. Small interference RNA targeting heat-shock protein 27 inhibits the growth of prostatic cell lines and induces apoptosis via caspase-3 activation in vitro. BJU Int. 2006; 98:1082-9.

14. Wyatt AW, Gleave ME. Targeting the adaptive molecular landscape of castration-resistant prostate cancer. EMBO Mol Med. 2015; 7:878-94.

15. Gibert B, Hadchity E, Czekalla A, Aloy MT, Colas P, Rodriguez-Lafrasse C, Arrigo AP, Diaz-Latoud C. Inhibition of heat shock protein 27 (HspB1) tumorigenic functions by peptide aptamers. Oncogene. 2011; 30:3672-81.

16. McConnell JR, McAlpine SR. Heat shock proteins 27, 40, and 70 as combinational and dual therapeutic cancer targets. Bioorg Med Chem Lett. 2013; 23:1923-8.

17. Kim EH, Lee HJ, lee DH, Bae S, Soh JW, Jeoung D, Kin J, Cho CK, Lee YJ and Lee YS: Inhibition of heat shock protein 27-mediated resistance to DNA damaging agents by a novel PKCdelta-V5 heptapeptide. Cancer Res. 2007; 67:6333-6341.

18. Lee HJ, Kim EH, Seo WD, Choi TH, Cheon GJ, Lee YJ, Lee YS. Heat shock protein 27-targeted heptapeptide of the PKCdelta catalytic V5 region sensitizes tumors with radioand chemoresistance. Int J Radiat Oncol Biol Phys. 2011; 80:221-30.

19. Gibert B ${ }^{1}$, Simon S, Dimitrova V, Diaz-Latoud C, Arrigo AP. Peptide aptamers: tools to negatively or positively modulate HSPB1 function. Philos Trans R Soc Lond B Biol Sci. 2013; 368:20120075.

20. Schmidt M, Pei L. Synthetic toxicology: where engineering meets biology and toxicology. Toxicol Sci. 2011; 120:S204-24.
21. Choi SH, Lee YJ, Seo WD, Lee HJ, Nam JW, Lee YJ, Kim J, Seo EK, Lee YS. Altered cross-linking of HSP27 by zerumbone as a novel strategy for overcoming HSP27mediated radioresistance. Int J Radiat Oncol Biol Phys. 2011; 79:1196-205.

22. Garrido $\mathrm{C}^{1}$, Brunet M, Didelot C, Zermati Y, Schmitt E, Kroemer G. Heat shock proteins 27 and 70: anti-apoptotic proteins with tumorigenic properties. Cell Cycle. 2006; 5:2592-601.

23. Heinrich JC1, Tuukkanen A, Schroeder M, Fahrig T, Fahrig R. RP101 (brivudine) binds to heat shock protein HSP27 (HSPB1) and enhances survival in animals and pancreatic cancer patients. J Cancer Res Clin Oncol. 2011; 137:1349-61.

24. Bruey JM, Ducasse C, Bonniaud P, Ravagnan L, Susin SA, Diaz-Latoud C, Gurbuxani S, Arrigo AP, Kroemer G, Solary E, Garrido C. Hsp27 negatively regulates cell death by interacting with cytochrome c. Nat Cell Biol. 2000; 2:645-52.

25. Paul C, Manero F, Gonin S, Kretz-Remy C, Virot S, Arrigo AP. Hsp27 as a negative regulator of cytochrome C release. Mol Cell Biol. 2002; 22:816-34.

26. Pandey P, Farber R, Nakazawa A, Kumar S, Bharti A, Nalin C, Weichselbaum R, Kufe D, Kharbanda S. Hsp27 functions as a negative regulator of cytochrome c-dependent activation of procaspase-3. Oncogene. 2000; 19:1975-81.

27. Gibert B, Eckel B, Fasquelle L, Moulin M, Bouhallier F, Gonin V, Mellier G, Simon S, Kretz-Remy C, Arrigo AP, Diaz-Latoud C. Knock down of heat shock protein 27 (HspB1) induces degradation of several putative client proteins. PLoS One. 2012; 7:e29719.

28. Charette SJ, Lavoie JN, Lambert H, Landry J. Inhibition of Daxx-mediated apoptosis by heat shock protein 27. Mol Cell Biol. 2000; 20:7602-12.

29. Wu R, Kausar H, Johnson P, Montoya-Durango DE, Merchant M, Rane MJ. Hsp27 regulates Akt activation and polymorphonuclear leukocyte apoptosis by scaffolding MK2 to Akt signal complex. J Biol Chem. 2007; 282:21598-608.

30. Rocchi P, Beraldi E, Ettinger S, Fazli L, Vessella RL, Nelson C, Gleave M. Increased Hsp27 after androgen ablation facilitates androgen-independent progression in prostate cancer via signal transducers and activators of transcription 3-mediated suppression of apoptosis. Cancer Res. 2005; 65:11083-93.

31. Andrieu C, Taieb D, Baylot V, Ettinger S, Soubeyran P, DeThonel A, Nelson C, Garrido C, So A, Fazli L, Bladou F, Gleave M, Iovanna JL, et al. Heat shock protein 27 confers resistance to androgen ablation and chemotherapy in prostate cancer cells through eIF4E. Oncogene. 2010; 29:1883-96.

32. Schmitt E, Gehrmann M, Brunet M, Multhoff G, Garrido C. Intracellular and extracellular functions of heat shock 
proteins: repercussions in cancer therapy. J Leukoc Biol. 2007; 81:15-27.

33. Ciocca DR, Calderwood SK. Heat shock proteins in cancer: diagnostic, prognostic, predictive, and treatment implications. Cell Stress Chaperones. 2005; 10:86-103.

34. Calderwood SK, Khaleque MA, Sawyer DB, Ciocca DR. Heat shock proteins in cancer: chaperones of tumorigenesis. Trends Biochem Sci. 2006; 31:164-72.

35. Heinrich JC, Tuukkanen A, Schroeder M, Fahrig T, Fahrig R. RP101 (brivudine) binds to heat shock protein HSP27 (HSPB1) and enhances survival in animals and pancreatic cancer patients. J Cancer Res Clin Oncol. 2011; 137:1349-61.

36. Kim LS, Kim JH. Heat shock protein as molecular targets for breast cancer therapeutics. J Breast Cancer. 2011; 14:167-74.

37. Stetler RA, Gao Y, Signore AP, Cao G, Chen J. HSP27: mechanisms of cellular protection against neuronal injury. Curr Mol Med. 2009; 9:863-72.

38. Hu Z, Zeng Q, Zhang B, Liu H, Wang W. Promotion of p53 expression and reactive oxidative stress production is involved in zerumbone-induced cisplatin sensitization of nonsmall cell lung cancer cells. Biochimie. 2014; 107:257-62.

39. Luke Whitesell, Susan L. Lindquist HSP90 and the chaperoning of cancer. Nature Reviews Cancer. 2005; 5:761-772.

40. Shinichi Takayama, John C Reed, Sachiko Homma. Heatshock proteins as regulators of apoptosis. Oncogene. 2003; 22:9041-9047.
41. Kamal A, Thao L, Sensintaffar J, Zhang L, Boehm MF, Fritz LC, Burrows FJ. A high-affinity conformation of Hsp90 confers tumour selectivity on Hsp90 inhibitors. Nature. 2003; 425:407-10.

42. Chiosis G, Huezo H, Rosen N, Mimnaugh E, Whitesell L, Neckers L. 17AAG: low target binding affinity and potent cell activity - finding an explanation. Mol Cancer Ther. 2003; 2:123-9.

43. Tanaka Y, Fujiwara K, Tanaka H, Maehata K, Kohno I. Paclitaxel inhibits expression of heat shock protein 27 in ovarian and uterine cancer cells. Int J Gynecol Cancer. 2004; 14:616-20.

44. Shi P, Wang MM, Jiang LY, Liu HT, Sun JZ. Paclitaxeldoxorubicin sequence is more effective in breast cancer cells with heat shock protein 27 overexpression. Chin Med J (Engl). 2008; 121:1975-9.

45. Song TF, Zhang ZF, Liu L, Yang T, Jiang J, Li P. Small interfering RNA-mediated silencing of heat shock protein 27 (HSP27) Increases chemosensitivity to paclitaxel by increasing production of reactive oxygen species in human ovarian cancer cells. J Int Med Res. 2009; 37:1375-88.

46. Yamamoto K, Okamoto A, Isonishi S, Ochiai K, Ohtake Y. Heat shock protein 27 was up-regulated in cisplatin resistant human ovarian tumor cell line and associated with the cisplatin resistance. Cancer Lett. 2001; 168:173-81. 